\title{
Vestibular-Nerve Inputs to the Vestibulo-ocular Reflex: A Functional-Ablation Study in the Squirrel Monkey
}

\author{
Lloyd B. Minor ${ }^{1,2}$ and Jay M. Goldberg ${ }^{1}$ \\ Departments of ${ }^{1}$ Pharmacological and Physiological Sciences (Neurobiology) and ${ }^{2}$ Surgery (Otolaryngology-Head and \\ Neck Surgery), University of Chicago, Chicago, Illinois 60637
}

\begin{abstract}
Advantage was taken of differences in the electrical excitability of vestibular-nerve tibers to characterize the afferent input to the canal-related vestibulo-ocular reflex. Large anodal (inhibitory) currents, when delivered to both ears, result in a selective, reversible ablation of irregular afferents. Their background discharge and responses to head rotations are temporarily abolished. The same currents have less effect on the background discharge and no effect on the rotational sensitivity of regular afferents. Eye movements were evoked by head rotations in alert monkeys. The ablating currents did not alter the ocular responses to sinusoidal head rotations in yaw or pitch planes. Responses to rapid changes in head velocity were similarly unaffected. It is concluded that irregular afferents do not make a net contribution to the reflex. Slow-phase eye movements evoked by unilateral galvanic currents are consistent with this conclusion. The results are incorporated into a systems model of the reflex. There are three conclusions from the model: (1) the signal to motoneurons consists of the sum of three components related, respectively, to head velocity, eye position, and filtered eye velocity; (2) regular afferents provide the best match to the dynamic requirements of the reflex; and (3) the central pathways responsible for all three signal components receive regular inputs.
\end{abstract}

Vestibular-ncrve afferents, including those innervating an individual semicircular canal, can differ in their discharge properties (Goldberg and Fernández, 1971). Some fibers have a regular spacing of action potentials. In others the spacing is irregular. The two kinds of fibers differ in their response dynamics. For frequencies $<0.1 \mathrm{~Hz}$, responses to sinusoidal head rotations conform to the torsion-pendulum model, which is thought to describe the displacement of the cupula and endolymph. At higher frequencies, where cupular displacement should parallel angular head velocity, afferent responses show a phase lead and a gain enhancement. These high-frequency effects are larger, the more irregular the discharge of the fiber.

\footnotetext{
Received Nov, 6, 1990; revised Jan. 8, 1991; accepted Jan. 11, 1991

This study was supported by NIH Grants DC 00070 and EY 07209 and by NASA Grant NAG 2-148. L.B.M. was supported by NINCDS Individual National Research Service Award F32 NS 07560 and by NASA Space Biology Research Award NAGW-70. J.M.G. is a Claude Pepper Awardee of the NIDCD. Julie Bertram assisted with care of the animals, and Curtiss Cohen helped in the development of the computer programs. A previous version of the manuscript was read by S. G. Lisberger, R. A. McCrea, and R. D. Tomlinson.

Correspondence should be addressed to Dr. Lloyd B. Minor, Department of Pharmacological and Physiological Sciences, University of Chicago, 947 East 58th Street, Chicago, IL 60637.

Copyright (C) 1991 Society for Neuroscience $0270-6474 / 91 / 111636-13 \$ 03.00 / 0$
}

What is the functional significance of this afferent diversity? One possibility is that the high-frequency phase leads of different afferents might allow them to compensate for the dynamic loads of the reflex pathways to which they contribute (Fernández and Goldberg, 1971; Bilotto et al., 1982). To determine which afferent input is best matched to the requirements of a reflex, three kinds of information are needed: (1) the overall performance of the reflex, (2) the dynamics of the motor plant, and (3) the transformation made by the brain in matching afferent input to motor load. The canal-related vestibulo-ocular reflex (VOR) provides an example. For frequencies $>0.1 \mathrm{~Hz}$, the VOR produces eye movements that are equal and opposite to head movements. The mechanics of the eyeball can be approximated by a first-order lag system, which is dominated by elastic forces at low frequencies and by viscous forces at high frequencies (Robinson, 1970). As was pointed out by Skavenski and Robinson (1972), the brain can compensate for first-order plant dynamics by delivering to ocular motoneurons the sum of two signals: (1) a head-velocity signal mirroring the discharge of vestibular-nerve afferents, and (2) an eye-position signal constructed by the mathematical integration of the head-velocity signal. Compensation is not perfect because the plant's mechanics introduce phase lags beyond those expected of a firstorder system. In addition, there are delays between head and eye movements. It has been suggested that the phase lags, both those due to plant mechanics and those due to reflex delays, can be compensated for by an afferent phase lead (Robinson, 1981). The required phase lead is small, similar to that of regularly discharging fibers. These afferents, then, would appear to provide a suitable input to the VOR (Goldberg et al., 1987; also see Discussion).

Evidence that the VOR receives a specific projection from regularly discharging afferents comes from recordings of canalrelated, presumed secondary neurons in the vestibular nuclei of alert monkeys. One class of secondary neurons has been identified as contributing to the middle link of the three-neuron VOR reflex pathway (King et al., 1976; McCrea et al., 1980; Tomlinson and Robinson, 1984). These are position-vestibular-phase (PVP) neurons, so-called because they carry eye-position as well as head-velocity (vestibular) signals and because they pause during saccades. When their responses to head rotations are compared to those of vestibular-nerve axons, PVP neurons have small phase leads, consistent with their getting most of their vestibular-nerve input from regular fibers (Fuchs and Kimm, 1975; Lisberger and Miles, 1980; Chubb et al., 1984; Tomlinson and Robinson, 1984). In contrast, secondary neurons not carrying eye-position signals can have large phase leads (Fuchs and Kimm, 1975; Tomlinson and Robinson, 1984), possibly indi- 
cating that they receive inputs from more irregular afferents The results are only suggestive for at least two reasons: (1) PVP cells may not be the only secondary neurons contributing to the reflex, and (2) differences in response dynamics of secondary neurons may reflect central as well as peripheral mechanisms.

A more direct way of evaluating the peripheral inputs to secondary neurons takes advantage of differences in the electrical excitability of vestibular-nerve fibers (Goldberg et al., 1984). The afferents' thresholds to short labyrinthine shocks show a large variation that is systematically related to discharge regularity: the more irregular a unit's firing, the lower its electrical threshold. Vestibular-evoked EPSPs are recorded from secondary vestibular neurons (Goldberg et al., 1987). By determining how the EPSP of a neuron grows with shock strength, one can ascertain the discharge regularity of the afferents making direct connections with it. As a class, secondary neurons contributing to the VOR get a higher proportion of their monosynaptic input from regular afferents than do those projecting to the cerebellum or to the spinal cord (Highstein et al., 1987; Boyle et al., 1991). The segregation of afferent inputs is incomplete, however: secondary VOR neurons receive an irregular input, which averages $>30 \%$ of the total monosynaptic excitatory drive they receive from the vestibular nerve.

In this paper, the afferent input to the VOR was characterized by studying the effects of labyrinthine galvanic currents on the overall operation of the reflex. Once again, differences in the afferents' electrical excitability were exploited. Constant currents alter ongoing afferent activity: cathodal currents increase discharge, and anodal currents decrease it (Goldberg et al., 1984). As is the case for short shocks, sensitivity to constant galvanic currents shows an orderly variation with discharge regularity: regular fibers are much less sensitive than are irregular fibers (Ezure et al., 1983; Goldberg et al., 1984). The currents were used in two ways:

First, unilateral galvanic currents were presented to alert squirrel monkeys, while the resulting horizontal nystagmus was monitored. The eye movements evoked by a group of afferents should reflect their galvanic sensitivities. Hence, smaller responses might be expected if the VOR received its afferent input from regular, as compared to irregular, fibers. Second, bilateral galvanic currents were used to obtain a selective and reversible ablation of irregular afferents. Large anodal (inhibitory) currents were delivered to both ears. The currents were of sufficient magnitude to silence irregularly discharging units, so much so that they became unresponsive to rotational stimuli. The effects were temporary, lasting only as long as the currents were present. Because the galvanic sensitivity of regular afferents is low, the same currents had only small effects on the latter units' background discharge and no effect on their rotational responses. Eye movements were evoked by head rotations in alert monkeys, both in the presence and in the absence of the ablating currents. In this way, the contribution of irregular afferents to the VOR could be determined. From work in anesthetized animals (Goldberg et al., 1984), it was estimated that a current of $100 \mu \mathrm{A}$ would suffice to achieve a selective, reversible ablation of irregular units. Recordings made from the vestibular nerve in one of the alert animals of the present study confirmed that this was the case.

Previous studies had indicated that $>30 \%$ of the monosynaptic vestibular-nerve input to secondary VOR neurons comes from irregularly discharging afferents (Highstein et al., 1987; Boyle et al., 1991). On this basis, we supposed that the eye movements evoked by unilateral currents would fall between those predicted for regular and irregular afferents. In a similar vein, it was anticipated that the functional ablation of irregular afferents would result in a significant decrease in VOR gain. The present study was designed to test these predictions. Neither prediction was confirmed. Rather, our results imply that the vestibular-nerve input to the VOR comes almost entirely from regular afferents.

\section{Materials and Methods}

Surgical preparation. Surgery was done under sterile conditions in five adult squirrel monkeys anesthetized with sodium pentobarbital $(15 \mathrm{mg} /$ $\mathrm{kg}$, i.p.). A head bolt was cemented to the occiput. A prefabricated search coil was implanted about the limbus of the right eye, and the leads were soldered to a plug cemented to the skull. Three weeks were allowed before proceeding with the implantation of labyrinthine stimulating electrodes in both ears. A postauricular incision was made. The cartilaginous external canal and the annulus of the tympanic membrane were dissected away from the bony canal to provide access to the middle ear. The handle of the malleus remained attached to the tympanic membrane, and care was taken not to disturb the other ossicles. A hand-held drill was used to make a hole in the bony promontory at a point midway between the round and oval windows. A chlorided silver wire, $250 \mu \mathrm{m}$ in diameter and insulated to within $1 \mathrm{~mm}$ of its tip, was fit through the hole and into the perilymphatic space of the vestibule. A second chlorided silver wire was placed in the ventral portion of the middle ear. The stimulating wires were brought through the external auditory meatus, covered with acrylic, and mated to a connector on the skull. The external canal and the tympanic membrane were then returned to their normal positions. Experiments began after a 3-week recovery period.

Eye-movement recording. Experiments took place in an enclosed chamber. The animal was seated in a plastic chair, and the head was restrained by securing the implanted bolt to a chair-mounted clamp. The chair was placed in a superstructure mounted to the top surface of a rotating table, whose motion was controlled by a velocity servomechanism (Inland model 823). The superstructure allowed the animal to be tilted, while the center of its head remained over the table's rotation axis. Testing of the horizontal vestibulo-ocular reflex (VOR) was done with the animal upright in the superstructure and with the horizontal canals in the earth-horizontal rotation plane. For testing the vertical VOR, the animal was pitched $90^{\circ}$ nose down and rolled $90^{\circ}$ right- or left-ear down. These maneuvers placed the animal's sagittal plane parallel to the rotation plane.

Two pairs of field coils, 15 inches in diameter, moved with the animal and generated magnetic fields alternating at $20 \mathrm{kHz}$. The horizontal and vertical fields were separated in spatial and temporal quadrature. Voltages induced in the scleral search coil were monitored by a detection circuit (Neurodata Instruments) that extracted signals proportional to horizontal and vertical eye positions. The peak-to-peak noisc at the output of the circuit was equivalent to an eye movement of $12 \mathrm{~min}$ of arc. Eye signals and the tachometer output of the rotating chair were passed through anti-aliasing filters with $200-\mathrm{Hz}$ cutoffs and digitized at a sampling rate of $500 \mathrm{~Hz}$ by 12-bit analog-to-digital converters interfaced to an LSI 11-73 computer.

The eye-coil system was calibrated at the beginning and end of each experimental session. Slow-phase eye velocities, evoked by $30 \mathrm{deg} / \mathrm{sec}$ horizontal and vertical optokinetic stimulation, were measured and were assumed to match target velocity. The calibration was verified in three animals, who were trained to get a liquid reinforcement if they fixated one of three small target lamps shortly after it was lit. A central target was located immediately in front of the animal; the other two were 8 deg to the right and left of center. The horizontal-eye position signals measured during fixation were within $7 \%$ of those predicted from optokinetic responses.

Electrical stimulation of the labyrinth. Constant currents, usually of 5 -sec duration, were delivered by a stimulus isolator (WPI 1850A) and monitored with an in-series digital ammeter. Currents are designated as cathodal (excitatory) or anodal (inhibitory) to indicate the polarity of the perilymphatic electrode.

Vestibulo-ocular reflex testing. Sinusoidal head rotations $(0.5 \mathrm{~Hz}, \pm 40$ $\mathrm{deg} / \mathrm{sec}$ and $4 \mathrm{~Hz}, \pm 20 \mathrm{deg} / \mathrm{sec}$ ) were presented in darkness. For the $0.5-\mathrm{Hz}$ stimuli, digitized eye positions were desaccaded and smoothed (for details, see Minor and Goldberg, 1990). Successive cycles, typically 


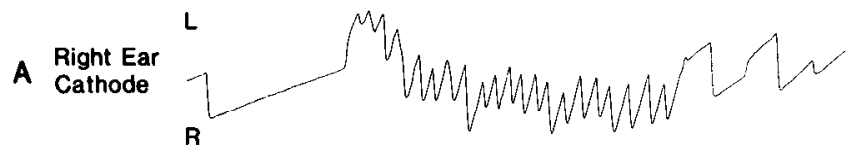

B Right Ear

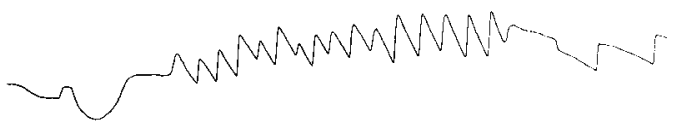

C Left Ear



Left Ear

Anode

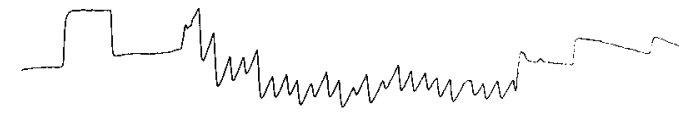

E

Both Ears
Anode
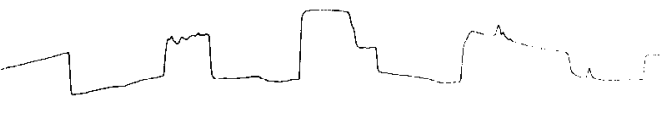

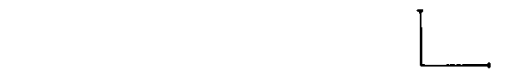

Current

Monitor

Figure 1. Horizontal nystagmus evoked in the dark by cathodal and anodal 100- $\mu \mathrm{A}$ current steps of 5-sec duration (see Current Monitor), delivered to the right ear $(A, B)$, to the left ear $(C, D)$, or to both ears $(E)$. Each record shows eye position with leftward $(L)$ and rightward $(R)$ movements as indicated. Calibration: vertical, 5 deg; horizontal, 1 sec

three to five in number, of the desaccaded eye-position record were averaged by calculating the mean eye position for each of 40 points equally spaced over the sine-wave cycle. Any linear trend in the singlecycle average was removed. The amplitude and phase of the response fundamental were obtained from a Fourier analysis, as were the corresponding values for the tachometer signal. Gains and phases are expressed with the convention that a unity gain and a zero phase imply a perfectly compensatory VOR. A positive phase indicates that eye movements lead table movements. Data from the $4-\mathrm{Hz}$ rotations were handled similarly, except that no desaccading was performed. Rather, only saccade-free cycles were used; averaging was done on 12-18 not necessarily consecutive cycles.

A rapid change in hcad vclocity was used to evaluate the early part of the horizontal VOR with finer time resolution. Animals, while in an upright position, fixated the central target lamp in an otherwise dark room. After the target had been acquired and held for $1 \mathrm{sec}$, it was extinguished, and $300 \mathrm{msec}$ later a velocity trapezoid was presented. The rotation table was accelerated in either the clockwise or the counterclockwise direction. The acceleration lasted $50 \mathrm{msec}$ and averaged $600 \mathrm{deg} / \mathrm{sec}^{2}$. After reaching a velocity plateau, the table continued to rotate at $30 \mathrm{deg} / \mathrm{sec}$ for $1 \mathrm{sec}$ and was then decelerated over a period of $50 \mathrm{msec}$ until it was stationary. Angular head velocity was monitored with a rate sensor (Watson Industries; bandwidth, $200 \mathrm{~Hz}, \mathrm{DC}$ ) mounted to the head clamp. To quantify eye movements, an eye-velocity signal obtained by analog differentiation of the original eye-position signal was used. The differentiator had a second-order, high-frequency filter with corner frequencies of 50 and $340 \mathrm{~Hz}$. Eyc-vclocity and head-velocity signals were digitized at a rate of $500 \mathrm{~Hz}$.

Vestibular-nerve recordings. A plastic recording chamber was implanted on one animal so that recordings could be made from the left vestibular nerve. The chamber was cleaned with sterile saline daily and was kept capped between recording sessions. Tungsten microelectrodes, coated with varnish to within $10-15 \mu \mathrm{m}$ of their tips, were inserted into a 22-gauge stainless-steel guide tube. Signals were amplified in a conventional fashion and recorded on an 8-channel FM analog tape recorder (bandwidth, $2500 \mathrm{~Hz}, \mathrm{DC}$ ) for later computer processing.

Punctures were placed $\approx 6 \mathrm{~mm}$ from the midline. The microelectrode
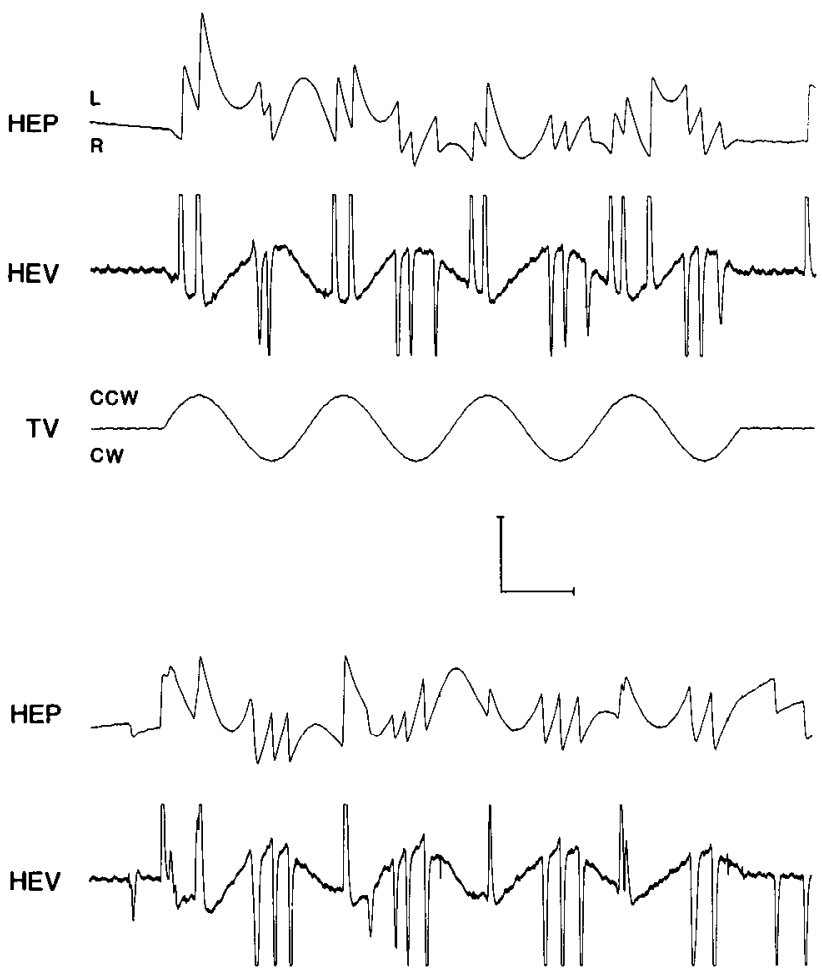

$\mathrm{CM}$

Figure 2. Horizontal VOR evoked by $0.5-\mathrm{Hz}, \pm 40 \mathrm{deg} / \mathrm{sec}$ rotations under control conditions (upper records) and during the functional ablation of irregular afferents (lower records). Rotations were in the yaw plane with the animal in darkness. Upper records, no currents; lower records, $100-\mu \mathrm{A}$ anodal currents were presented to both ears as indicated in current monitor (CM). HEP, horizontal eye position; $H E V$, horizontal eye velocity; $T V$, table velocity (tachometer signal) in clockwise $(C W)$ and counterclockwise (CCW) directions. For HEP, HEV, and TV, leftward $(L)$ movements are upward; rightward $(R)$ movements, downward. Calibration: vertical, $12 \mathrm{deg}$ for $H E P, 80 \mathrm{deg} / \mathrm{sec}$ for. $H E V$; horizontal, 1 sec.

and guide tube were advanced as a unit beyond the cerebellar tentorium by a micromanipulator attached to the recording chamber. A hydraulic stepping microdrive was then used to move the microelectrode out of the guide tube and into the cerebellum. The sequence of unitary potentials encountered during the puncture was similar to that previously described for the rhesus monkey (Keller, 1976; Louie and Kimm, 1976). The electrode first passed through a zone of presumed Purkinje cells, whose firing was modulated with eye movements. Next there was a region, $\approx 200 \mu \mathrm{m}$ in depth, where no activity was encountered. Below this, the electrode entered the vestibular nerve, which was characterized by positive-going, short-duration spikes firing at high frequency. Within the vestibular nerve, only units responding to head rotations and head tilts were found; none of the units had oculomotor-related activity. It was possible to entrain unit firing to labyrinthine shocks. The lowest threshold for activation was $50 \mu \mathrm{A}$, and the shortest latency from the onset of the shock to that of the action potential was $0.3 \mathrm{msec}$.

During recording sessions, the animal was alert, but no behavioral tasks were imposed. It was pitched nose up so that the horizontal canals were inclined $30^{\circ}$ from the rotation plane. Once an afferent was isolated, the table was manually rotated in clockwise and counterclockwise directions. Only rotation-sensitive units were studied. In the nose-up position, afferents innervating the left vertical canals are excited by clockwise rotations, whereas those innervating the left horizontal canal are excited by counterclockwise rotations. For each afferent, a 5-sec sample of background discharge was recorded, followed by the response to three cycles of a $0.5-\mathrm{Hz}, \pm 40 \mathrm{deg} / \mathrm{sec}$ rotation. The sequence was repeated twice: first with no galvanic currents and then with $100-\mu \mathrm{A}$ anodal currents delivered to both ears. Responses to the second sinusoidal cycle 
were used. The gain and phase of the fundamental component, both stated with respect to head velocity, were obtained from a Fourier analysis. Gains were multiplied by a constant factor to convert them to the rotational gains cxpected had the canal been aligned with the rotation plane. The factor was 1.15 for horizontal-canal units and 2.83 for vertical-canal units.

A coefficient of variation $\left(\mathrm{CV}^{*}\right)$, normalized to a mean interval of 15 msec, was calculated from the background discharge (Goldberg et al., $1984)$. Units were categorized as regular $\left(\mathrm{CV}^{*}<0.10\right)$, intermediate $\left(0.10 \leq \mathrm{CV}^{*} \leq 0.20\right)$, or irregular $\left(\mathrm{CV}^{*}>0.20\right)$.

\section{Results}

Eye movements evoked by unilateral galvanic currents

When galvanic currents were delivered to one or the other ear, a horizontal nystagmus resulted (Fig. 1). Slow phases were contralaterally directed for cathodal (excitatory) currents (Fig. $1 A, C$ ) and ipsilaterally directed for anodal (inhibitory) currents (Fig. $1 B, D)$. The nystagmus persisted throughout the 5 -sec stimulus presentation. A smaller nystagmus in the same direction was seen during the first $2-4 \mathrm{sec}$ of the poststimulus period. There was no vertical component to the nystagmus. Because the anterior and posterior canals are almost equally affected by the currents (Goldberg et al., 1984), a torsional component would be expected, but no attempt was made to measure it. Bilateral cathodal or anodal stimuli of equal magnitude resulted in no nystagmus (Fig. $1 E$ ).

Similar responses were seen in four animals; each of them was tested two or three times and its results averaged. $\Lambda$ spontaneous nystagmus with a small slow-phase velocity $(<4 \mathrm{deg} /$ sec) was sometimes present (Fig. 1). In quantifying the responses, the prestimulus slow-phase velocity was subtracted from the perstimulus value. Cathodal currents of $100 \mu \mathrm{A}$ resulted in a slow-phase velocity of $34.5 \pm 5.5 \mathrm{deg} / \mathrm{sec}$ when given to the left ear and $33.1 \pm 4.9 \mathrm{deg} / \mathrm{sec}$ when given to the right ear (mean $\pm \mathrm{SD} ; n=4$ ). For $100-\mu \mathrm{A}$ anodal currents, the corresponding values were $20.2 \pm 4.2 \mathrm{deg} / \mathrm{sec}$ (left ear) and $21.1 \pm 3.8 \mathrm{deg} /$ sec (right ear). Responses to cathodal stimuli were consistently larger than those to anodal stimuli; the anodal-to-cathodal ratio of slow-phase velocities averaged $0.63 \pm 0.10$ in the four animals.

\section{Functional ablation of irregular afferents}

Large (100- $\mu \mathrm{A})$ anodal currents were presented bilaterally. The ablating currents did not lead to detectable alterations in the VOR.

Sinusoidal head rotations. Figure 2 shows eye-movement responses to $0.5-\mathrm{Hz}, \pm 40 \mathrm{deg} / \mathrm{sec}$ horizontal head rotations for one animal. There is no obvious difference when the bilateral anodal currents are present (Fig. 2, lower records) or absent (Fig. 2 , upper records). This is confirmed by quantitative analysis. The eye-position signals of Figure 2 were desaccaded and smoothed, and successive cycles were averaged. Figure 3 shows the averaged responses when the currents were present (open circles) and absent (solid circles); the two curves are superimposable. Gains, obtained by Fourier analysis, are 0.83 and 0.84 , and phases are $-0.9 \mathrm{deg}$ and $-1.1 \mathrm{deg}$, currents present and absent, respectively. As was typical, harmonic distortion was small $(\approx 3 \%)$ and was unaffected by the currents.

The horizontal VOR evoked by $4.0-\mathrm{Hz}, \pm 20 \mathrm{deg} / \mathrm{sec}$ rotations is displayed in Figure 4 for another animal. Here, too, there is no discernible difference with (Fig. 4, lower records) or without the currents (Fig. 4, upper records); gains were 0.93 and 0.95 , and phases were $5.4^{\circ}$ and $6.3^{\circ}$, with and without currents, respectively.



Figure 3. Horizontal eye position versus sinusoidal phase angle (in degrees) obtained by desaccading, smoothing, and averaging three cycles of a $0.5-\mathrm{Hz}_{7},+40 \mathrm{deg} / \mathrm{sec}$ rotation. Solid circles, control conditions; open circles, irregular afferents were functionally ablated by presenting $100-$ $\mu \mathrm{A}$ anodal currents to both ears. Vertical calibration, $3 \mathrm{deg}$.

Table 1 summarizes data obtained from all animals for 0.5 and $4-\mathrm{Hz}$ horizontal rotations and for $0.5-\mathrm{Hz}$ vertical rotations. For each animal, tests were repeated three times and the results averaged. The currents did not significantly change the gain or phase for any of the three testing conditions. The data in Table 1 were used to compute $95 \%$ confidence intervals for the gains in the presence of the ablating currents. The confidence intervals, expressed as a percentage of the normal gains, were $4 \%$ for each of the two horizontal tests and $14 \%$ for the vertical test. These values can be viewed as the maximal reductions in gain that are statistically consistent with our results.

Rapid changes in head velocity. Velocity trapezoids were used (Fig. 5). The resulting horizontal VOR consisted of a contralaterally directed slow phase, $\approx 250 \mathrm{msec}$ in duration, followed by an ipsilaterally directed quick phase and then by a slow phase lasting almost until the end of the trapezoid. Eye-velocity signals, averaged for several stimulus repetitions, were analyzed with a temporal resolution of $2 \mathrm{msec}$. Control and ablation trials were interleaved. Figure 6 displays the averaged responses in one animal for 12 trials of each kind: control (solid circles) and experimental responses (open circles) are indistinguishable, cven during the first $10 \mathrm{msec}$ of the reflex.

Similar findings were obtained in three animals; in each of them, the effects of the ablating currents were studied in three separate experimental sessions and the results pooled. Responses began after a latent period of $14 \pm 2 \mathrm{msec}$ (mean \pm $\mathrm{SD} ; n=3$ ), and the eye velocity showed an overshoot before reaching a plateau. The plateau gain was $0.90 \pm 0.11$. Anodal currents had no discernible effect on the latent period, the initial response trajectory, the overshoot, or the plateau gain.

\section{Responses of individual afferents to galvanic currents}

The negative results of the functional-ablation study raised a question as to whether the galvanic currents were working in alert animals, as they had in anesthetized preparations (Goldberg et al., 1984). To determine this, extracellular recordings 

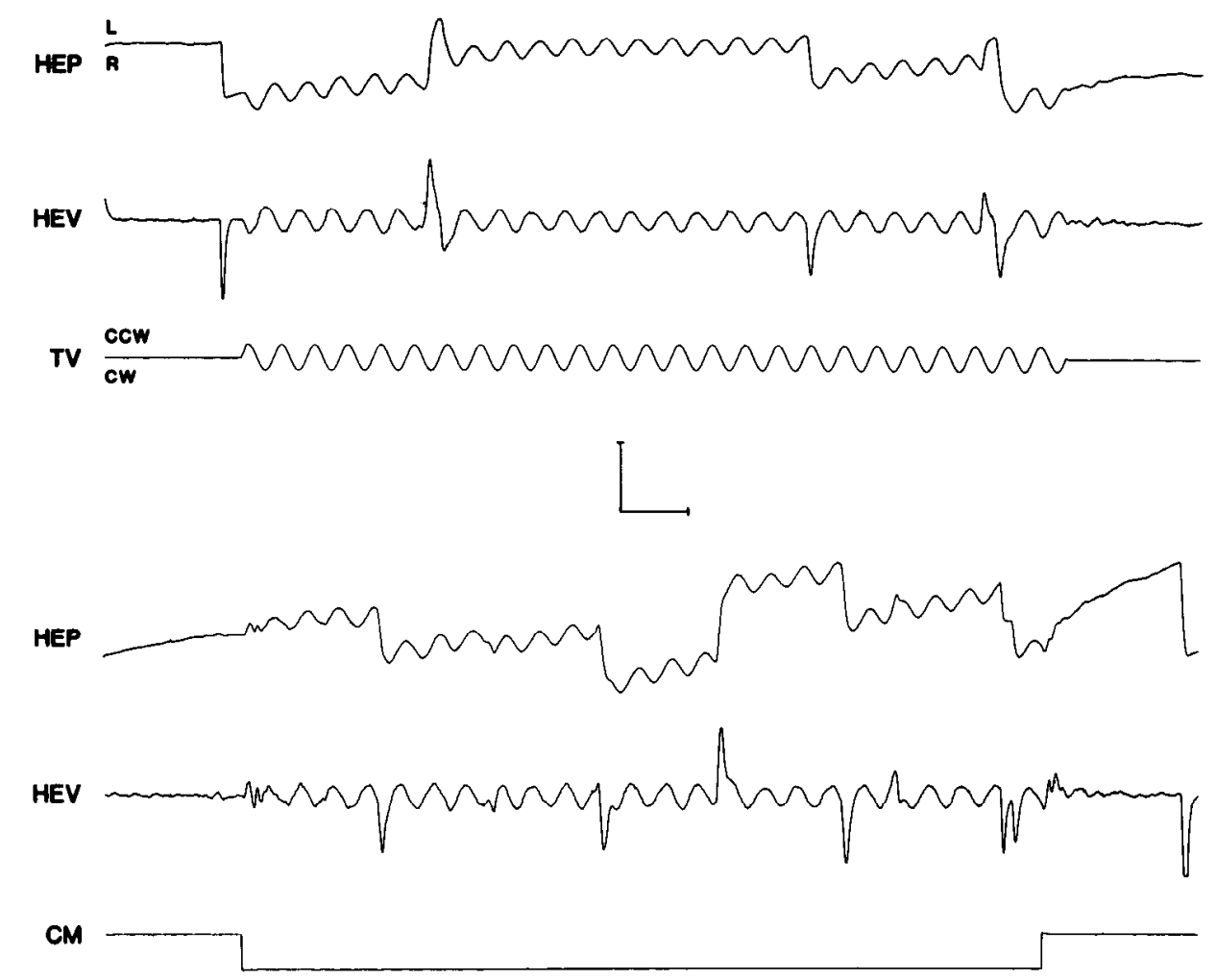

Figure 4. Horizontal VOR evoked in darkness by $4-\mathrm{Hz}, \pm 20 \mathrm{deg} / \mathrm{sec}$ rotations under control conditions (upper records) and during the functional ablation of irregular afferents (lower records). See Figure 2 for details. Calibration: vertical, $9 \mathrm{deg}$ for $H E P, 100$ $\mathrm{deg} / \mathrm{sec}$ for $H E V$; horizontal. $0.5 \mathrm{sec}$.

spikes/sec. In the absence of currents, the average rate during the rotation was $111 \mathrm{spikes} / \mathrm{sec}$, and the rotational gain was 0.54 spikes $\cdot \sec ^{-1} / \mathrm{deg} \cdot \mathrm{sec}^{-1}$ (Fig. $7 A$ ). When $100-\mu \mathrm{A}$ anodal currents were introduced bilaterally, the average rate was reduced by 10 spikes/sec, but the rotational gain was unaltered (Fig. $7 B$ ). The irregular afferent had a background discharge of 85 spikes/sec
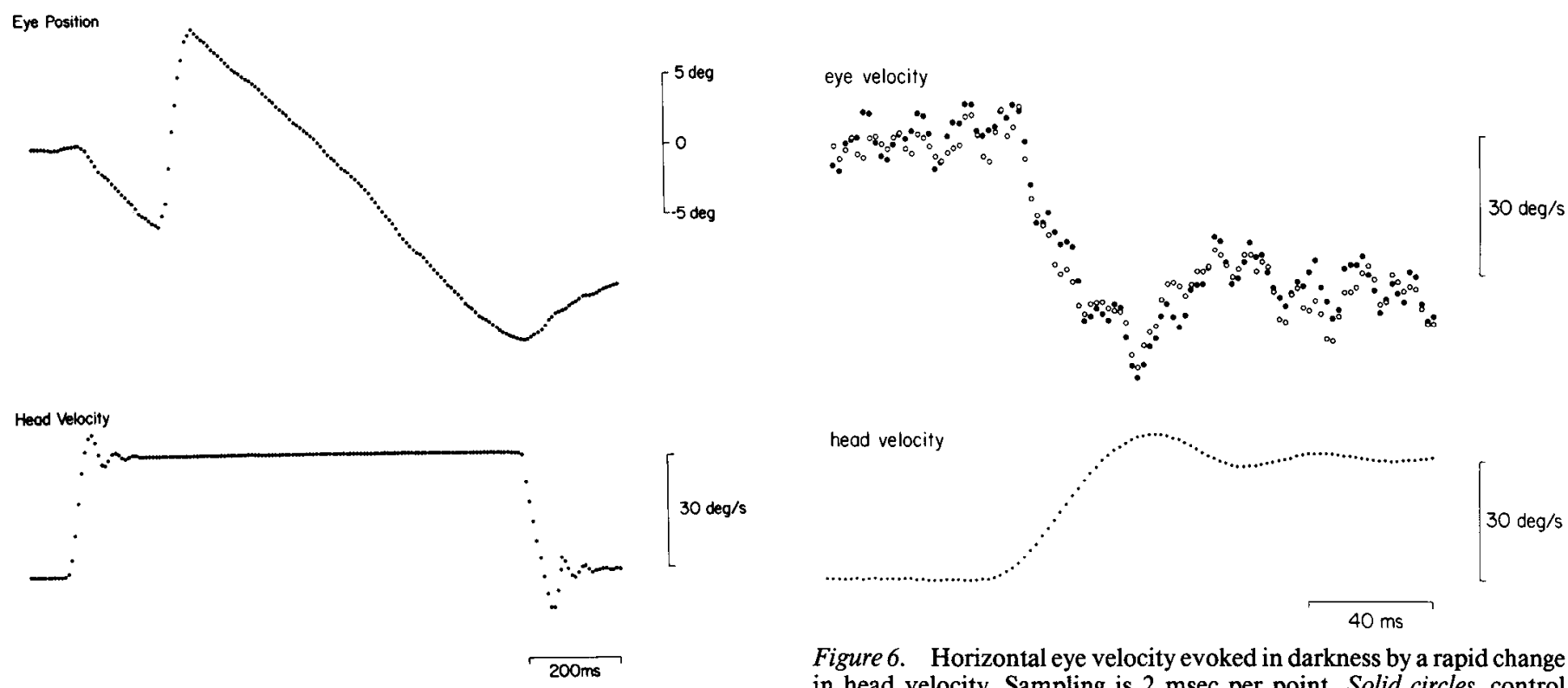

Figure 5. Horizontal eye movement evoked by a velocity trapezoid. Rotations were in the yaw plane with the animal in darkness. The initial head movement was clockwise, which resulted in a leftward movement of the eye. Upper trace, eye position; lower trace, head velocity monitored with a rate sensor.

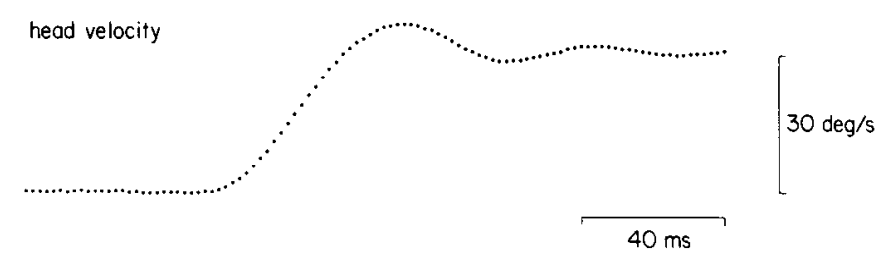

Figure 6. Horizontal eye velocity evoked in darkness by a rapid change in head velocity. Sampling is 2 msec per point. Solid circles, control conditions; open circles, irregular afferents were functionally ablated by 100- $\mu \mathrm{A}$ anodal currents presented to both ears. For each set of points, the eye velocity was averaged for 12 clockwise rotations. Experimental and control trials were interleaved. Head velocity was monitored with a rate sensor. 
Table 1. Normal VOR and its change with the functional ablation of irregular vestibular-nerve afferents

\begin{tabular}{|c|c|c|c|c|c|c|}
\hline \multirow[b]{2}{*}{ Reflex } & \multirow[b]{2}{*}{ Sinusoidal frequency } & \multirow[b]{2}{*}{$N$} & \multicolumn{2}{|l|}{ Gain } & \multicolumn{2}{|c|}{ Phase (degrees) } \\
\hline & & & Normal & $\begin{array}{l}\text { Effect of } \\
\text { ablation }\end{array}$ & Normal & $\begin{array}{l}\text { Effect of } \\
\text { ablation }\end{array}$ \\
\hline Horizontal & $\begin{array}{l}0.5 \mathrm{~Hz} \\
4.0 \mathrm{~Hz}\end{array}$ & $\begin{array}{l}4 \\
4\end{array}$ & $\begin{array}{l}0.82 \pm 0.10 \\
0.92 \pm 0.11\end{array}$ & $\begin{array}{r}0.01 \pm 0.03 \\
-0.00 \pm 0.04\end{array}$ & $\begin{array}{r}-1.7 \pm 1.0 \\
4.6 \pm 1.1\end{array}$ & $\begin{array}{l}0.0 \pm 1.1 \\
0.0 \pm 1.6\end{array}$ \\
\hline Vertical & $0.5 \mathrm{~Hz}$ & 3 & $0.81 \pm 0.04$ & $-0.02 \pm 0.08$ & $-0.9 \pm 9.0$ & $-0.4 \pm 2.8$ \\
\hline
\end{tabular}

The horizontal and vertical VORs were tested in the dark at the stated frequencies in $N$ subjects. Gains and phases (means $\pm \mathrm{SD}$ ) are used to characterize the normal reflexes; the effects of presenting 100- $\mu \mathrm{A}$ anodal currents to both ears are stated as changes from the normal values, with positive values indicating an increase in gain or a phase lead.

and a rotational gain of 2.1 spikes $\cdot \mathrm{sec}^{-1} / \mathrm{deg} \cdot \mathrm{sec}^{-1}($ Fig. $7 \mathrm{C})$. Its $\mathrm{CV}^{*}$ was 0.34 . The currents silenced the unit and eliminated its rotational response (Fig. $7 D$ ).

Data are summarized in Table 2 for 41 afferents recorded in this animal. Anodal currents had only a small effect on the background discharge of regular units and a negligible effect on their rotational responses. There were 18 irregular units recorded in the alert animal. They were, with one exception, silenced by the currents and made temporarily unresponsive to head rotations. Three of six intermediate units were silenced, and on average, rotational gains were diminished by $\approx 50 \%$. One point, not determined in previous studies, is that the currents had little influence on the phase of rotational responses. The average $( \pm S D)$ change in phase was $-0.7 \pm 3.0 \mathrm{deg}$ for 17 regular units and $1.2 \pm 1.4$ deg for 3 intermediate units. Only one irregular unit had a rotational response when the currents were present; it had a gain of $0.6 \mathrm{spikes} \cdot \mathrm{sec}^{-1} / \mathrm{deg} \cdot \mathrm{sec}^{-1}$ and a phase of $11 \mathrm{deg}$, which may be compared to control values of $1.6 \mathrm{spikes} \cdot \mathrm{sec}^{-1} / \mathrm{deg}$. $\mathrm{sec}^{-1}$ and $20 \mathrm{deg}$.

The afferent recordings from the one alert animal indicate that the currents were acting as expected. It is important, then, that the eye-movement results obtained from this animal were typical. Unilateral galvanic currents delivered to the recorded (left) ear resulted in horizontal slow-phase eye velocities of 30 $\mathrm{deg} / \mathrm{sec}$ (cathodal) and $14 \mathrm{deg} / \mathrm{sec}$ (anodal), values slightly smaller than those obtained for the other ear of this animal (33 and $19 \mathrm{deg} / \mathrm{sec}$, respectively) or for the other three animals (34 and $22 \mathrm{deg} / \mathrm{sec}$, respectively). In the recorded animal, there were negligible effects of bilateral $100-\mu \mathrm{A}$ anodal currents on the VOR produced by $0.5-\mathrm{Hz}$ horizontal and vertical sinusoidal rotations or by $4-\mathrm{Hz}$ horizontal rotations. Rapid head movements were not tested in this animal. Based on the eye movements evoked by unilateral currents, the stimulating electrodes in the recorded ear were, if anything, less effective than were those in the three animals that were so tested. Hence, the currents are likely to have eliminated the discharge of irregular afferents in the other animals, even though the reflex responses to rapid head movements were unaffected by the ablation. From these results, we conclude that the VOR appears entirely normal in the almost complete absence of inputs from irregular afferents combined with a substantial reduction of inputs from intermediate units.

\section{Discussion}

\section{Unilateral galvanic currents}

The use of unilateral currents was motivated by the notion that the eye movements evoked by a group of afferents should reflect their galvanic sensitivities. On this basis, it was supposed that regular fibers should give rise to smaller responses than should irregular fibers. The situation is, in reality, more complicated than we originally envisioned. If the eye movements were entirely determined by the response of a specific set of afferents, the expected slow-phase eye velocity ( $\dot{e}$ in $\mathrm{deg} / \mathrm{sec}$ ) will be given by

$$
\dot{e}=(1 / 2) \cdot I \cdot\left(\beta / g_{\mathrm{ROT}}\right) \cdot g_{\mathrm{VOR}},
$$

in which $I$ (in $\mu \mathrm{A}$ ) is the current delivered to the labyrinth, $\beta$ (in spikes $\cdot \sec ^{-1} / \mu \mathrm{A}$ ) is the galvanic sensitivity of the fibers, $g_{\text {ROT }}$ (in spikes $\cdot \sec ^{-1} / \mathrm{deg} \cdot \sec ^{-1}$ ) is their rotational sensitivity, and $g_{\mathrm{vOR}} \approx 0.8$ is the gain of the VOR (Paige, 1983; Minor and Goldberg, 1990). The equation assumes that the brain interprets the afferents' responses to galvanic currents and to head rotations in the same way. The factor of $1 / 2$ is introduced because rotations, unlike unilateral galvanic currents, cause oppositely directed responses on the two sides, and it is the difference in these responses that is used in estimating angular head velocity. As the equation indicates, $\dot{e}$ depends on the ratio $\beta / g_{\text {Ror }}$, not merely on $\beta$.

This last consideration is important because of the recent

Table 2. Effects of anodal galvanic currents on semicircular-canal afferents in the squirrel monkey

\begin{tabular}{|c|c|c|c|c|c|c|}
\hline \multirow[b]{2}{*}{ Afferents } & \multirow[b]{2}{*}{$N$} & \multirow[b]{2}{*}{$\mathrm{CV}^{*}$} & \multirow[b]{2}{*}{$\begin{array}{l}\text { Background } \\
\text { discharge } \\
\text { (spikes/sec) }\end{array}$} & \multicolumn{3}{|c|}{$100-\mu \mathrm{A}$ anodal currents } \\
\hline & & & & $\begin{array}{l}\text { Percent } \\
\text { normal } \\
\text { background }\end{array}$ & $\begin{array}{l}\text { Percent } \\
\text { units } \\
\text { silenced }\end{array}$ & $\begin{array}{l}\text { Percent } \\
\text { normal } \\
\text { gain }\end{array}$ \\
\hline Regular & 17 & 0.04 & 114 & 89 & 0 & 101 \\
\hline Intermediate & 6 & 0.14 & 138 & 23 & 50 & 54 \\
\hline Irregular & 18 & 0.42 & 84 & 5 & 94 & 3 \\
\hline
\end{tabular}


Figure 7. Two horizontal-canal afferents recorded from the vestibular nerve of an alert squirrel monkey. Each histogram plots discharge rates during 0.1 sec bins; shown is 1 sec of background discharge, followed by the response to three cycles of a $0.5-\mathrm{Hz}, \pm 40 \mathrm{deg} / \mathrm{sec}$ sinusoidal head rotation, and then by a 4 -sec poststimulus period. $A$ and $B$ show responses for a regularly discharging afferent, and $C$ and $D$, for an irregularly discharging afferent. For either unit, responses are compared under control conditions $(A, C)$ and during the presentation of $100-\mu \mathrm{A}$ anodal currents to both ears $(B, D$, solid line on abscissa). The currents lower the discharge of the regular unit but do not affect its rotational response. The irregular unit is silenced, and its rotational response is abolished.
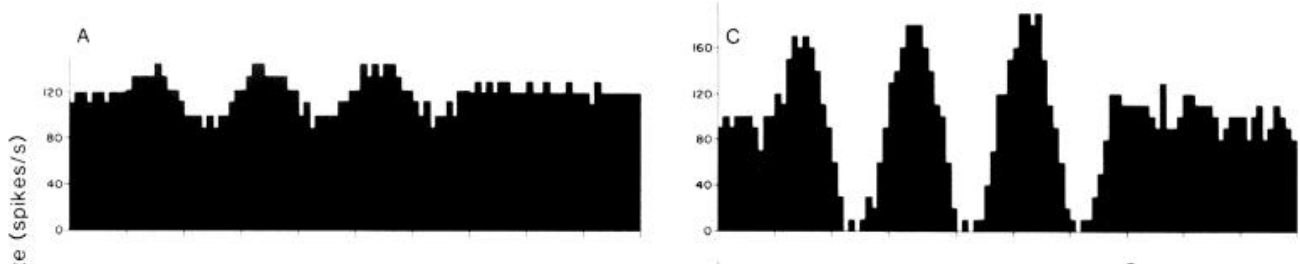

B
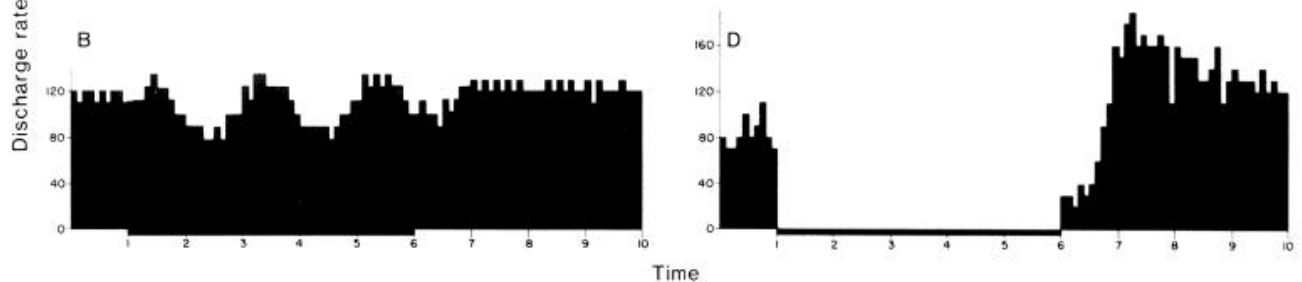

demonstration that there are two classes of canal afferents (Baird et al., 1988; Lysakowski et al., 1988). The first class includes regular and intermediate units, as well as irregular units with high rotational gains. The second class consists of irregular units with low rotational gains. Relevant data for the two classes are summarized in Table 3. For all units, $\beta$ increases, the more irregular the discharge and the higher the $\mathrm{CV}^{*} . g_{\text {ROT }}$ parallels $\beta$ for class 1 units, so the ratio $\beta / g_{\text {ROT }}$ remains nearly constant. Class 2 units have high galvanic sensitivities and relatively low rotational gains, with the result that their $\beta / g_{\text {ROT }}$ ratio is approximately four times higher than that of class 1 units.

The present results are more in line with the VOR receiving its input from class 1 units. Table 3 includes predicted slowphase velocities based on the galvanic responses recorded from vestibular-nerve fibers in anesthetized animals. For $100-\mu \mathrm{A}$ cathodal currents, the predicted values are $\approx 30 \mathrm{deg} / \mathrm{sec}$ for class 1 fibers, similar to those actually observed. We found that the slow phases evoked by anodal currents were approximately twothirds as large as the corresponding cathodal responses. The asymmetry can be explained by a similar asymmetry in the galvanic responses of regular or intermediate units (Table 3). A larger asymmetry is predicted for irregular units, mainly because their anodal responses are limited by inhibitory silencing.

Although the results are consistent with the VOR receiving a specific input from regular afferents, there are two difficulties with this interpretation. First, class 1 units include intermediate and irregular, as well as regular, units. The predicted slow-phase velocities are similar for all these afferents. At most, one might be tempted to exclude class 1 irregular units because their anodal-to-cathodal response asymmetries are larger than those seen in the evoked eye movements. Second, galvanic currents result in an unnatural pattern of discharge in the vestibular nerve (Goldberg et al., 1984). Not only are the five end organs affected almost equally, but the difference in responses of regular and irregular units innervating a single canal is much larger than is seen with rotational head movements. The small slow-phase eye velocities evoked by galvanic currents may reflect the unusual pattern of activity, rather than a specific afferent input to the reflex.

\section{Comparison of functional-ablation and intracellular-recording paradigms}

The functional-ablation study is easier to interpret than are the eye movements evoked by unilateral galvanic currents. This is especially so because the VOR was unaltered by the ablating currents. The results place limits on the contributions of intermediate and irregular afferents to the reflex. Vestibular-nerve responses have been studied in anesthetized animals (Goldberg

Table 3. Discharge characteristics of semicircular-canal afferents in the squirrel monkey





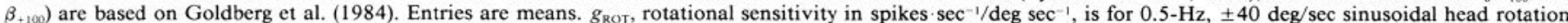

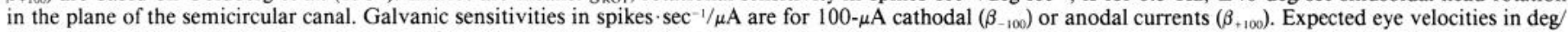

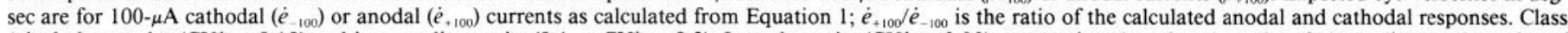

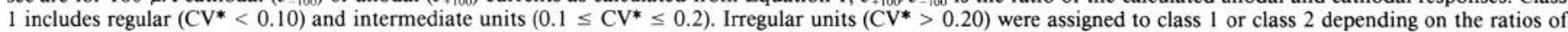
their rotational and galvanic sensitivities (see Baird et al., 1988). 
et al., 1984; Lysakowski et al., 1988) and in one alert animal (Table 2). Both sets of data indicate that $100-\mu \mathrm{A}$ anodal currents reduce the head-velocity signals of irregular units by almost $100 \%$ and those of intermediate units by $\approx 50 \%$. At the same time, the currents have a negligible effect on VOR gain; the maximal gain reduction that is statistically consistent with our results is $\approx 5 \%$ (Table 1 ). Assuming a linear summation of the signals from the various afferent contingents, this would imply that irregular afferents could contribute no more than $5 \%$ of the input to the reflex; the corresponding figure for intermediate units is $10 \%$.

A different picture was obtained in previous studies, where EPSPs evoked by ipsilateral vestibular-nerve $\left(V_{i}\right)$ stimulation were recorded from secondary VOR neurons (Highstein et al., 1987; Boyle et al., 1991). In the latter studies, it was estimated that $>30 \%$ of the monosynaptic $V_{i}$ input to these neurons comes from irregular afferents. There are at least three possible explanations for the apparent discrepancy between the two sets of experiments.

Otolith inputs. Both short shocks and constant galvanic currents affect all five end organs about equally (Goldberg et al., 1984). One possibility is that the low-threshold, irregular component of the monosynaptic EPSPs comes mainly from otolith afferents. Such an otolith contribution would not have been measured in the functional-ablation study, which used rotational stimuli that only influence the semicircular canals. A difficulty with the explanation relates to the limited distribution of otolith afferents within the vestibular nuclei. Secondary VOR neurons arise from at least two regions, the superior vestibular nucleus (SV) and a more caudal region that includes the ventral lateral vestibular nucleus (VLV) and adjaccnt parts of the medial and descending nuclei (for review, see Highstein and McCrea, 1988). Anatomical studies indicate that there is a direct otolith projection to VLV, but not to SV (Stein and Carpenter, 1967; Gacek, 1969; Kevetter and Peracchio, 1986), yet the irregular contribution to monosynaptic $V_{i}$ EPSPs is almost as great for VOR neurons in SV (Highstein et al., 1987), as it is for those in VLV (Boyle et al., 1991). In short, the evidence suggests that there is a substantial monosynaptic input from irregular canal afferents to secondary VOR neurons, at least for those in SV.

Vestibular-nerve inputs to various classes of secondary neurons. PVP cells may not be the only secondary vestibular neurons contributing to the middle link of the three-neuron VOR reflex pathway (Tomlinson and Robinson, 1984). One might conjecture that most of the $V_{i}$ canal inputs to PVP neurons come from regular afferents, whereas those to other classes of oculomotor-projecting secondary ncurons are more irregular. Studies of the $V_{i}$ EPSPs recorded from secondary VOR neurons provide little support for this suggestion (Highstein et al., 1987; Boyle et al., 1991). The intracellular data can be used to estimate the relative number of secondary VOR neurons receiving a small enough fraction of their monosynaptic $V_{i}$ input from irregular fibers to account for the results of the functional-ablation studies, namely, that $<5 \%$ of the input to the VOR comes from irregular afferents. Only $5-10 \%$ of VOR neurons meet the $<5 \%$ criterion. The proportion is so small that it seems unlikely that PVP neurons (or any other significant class of secondary VOR neurons) receive a nearly exclusive regular input.

Disynaptic vestibular-nerve inputs to secondary neurons. Besides a monosynaptic vestibular-nerve projection, secondary neurons get $V_{i}$ disynaptic excitatory (Precht and Shimazu, 1965; Wilson et al., 1968; Kawai et al., 1969) and inhibitory inputs
(Goldberg et al., 1987). Commissural pathways deliver di- and trisynaptic inhibitory inputs from the contralateral vestibular nerve (Shimazu and Precht, 1966; Shimazu, 1972; Goldberg et al., 1987). A convergence of direct and indirect inputs onto secondary VOR neurons can explain the seeming discrepancy between the results of the intracellular and functional-ablation studies. This can be illustrated by a specific example (Fig. 8). A hypothetical secondary VOR neuron (Fig. 8, 3) is shown receiving monosynaptic $V_{i}$ inputs (1), as well as disynaptic $V_{i}$ excitatory (2a) and inhibitory (2b) inputs, all coming from a single semicircular canal. Intracellular techniques would indicate that the secondary neuron receives one-third of its monosynaptic $V_{i}$ input from irregular afferents, yet the net signal carried by the neuron is entirely of regular origin and should be unaffected by an ablation of irregular afferents. This circumstance is accomplished in two ways: (1) the disynaptic excitatory inputs are weighted towards the regular end of the afferent spectrum and dilute irregular monosynaptic inputs, and (2) the $V_{i}$ inhibitory input is adjusted to cancel the irregular signals of the other two, excitatory, pathways.

\section{Organization of VOR pathways}

The results of the present study indicate that, of the entire population of vestibular-nerve fibers, only regularly discharging afferents make a net contribution to the VOR. The response dynamics of these fibers have been characterized both in the squirrel monkey (Goldberg and Fernández, 1971; Lysakowski et al., 1988) and in the rhesus monkey (Keller, 1976; Louie and Kimm, 1976; Lisberger and Pavelko, 1986). A relatively precise characterization of the mechanics of the oculomotor plant in the latter species is also available (Fuchs et al., 1988). This places us in a position to specify the transformation imposed by the brain in matching the afferent input to the motor load.

As is illustrated in Figure 9, the transfer function relating eye velocity to head velocity $\left(H_{\mathrm{VOR}}\right)$ can be expressed as the product of the transfer functions for semicircular-canal afferents $\left(H_{C}\right)$, for the brain $\left(H_{B}\right)$, and for the oculomotor plant or eye $\left(H_{E}\right)$.

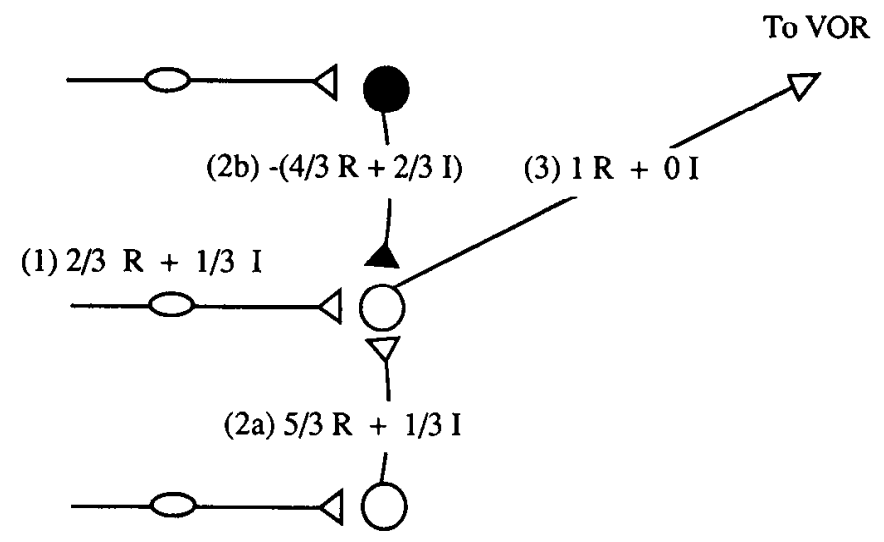

Figure 8. A schematic diagram of the ipsilateral semicircular-canal related inputs converging on a hypothetical secondary VOR neuron (3). These include a monosynaptic excitatory pathway $(I)$, a disynaptic excitatory pathway $(2 a)$, and a disynaptic inhibitory pathway $(2 b)$. For each pathway, head-velocity gains are stated separately for the response components related to regular $(R)$ and irregular $(I)$ vestibular-nerve inputs. The gains, which are merely illustrative, are arranged so that the disynaptic excitatory pathway dilutes the irregular monosynaptic inputs and the disynaptic inhibitory pathway cancels the irregular signals on the other two pathways. 
Semicircular
canals Brain $\begin{gathered}\text { Oculomotor } \\ \text { plant }\end{gathered}$

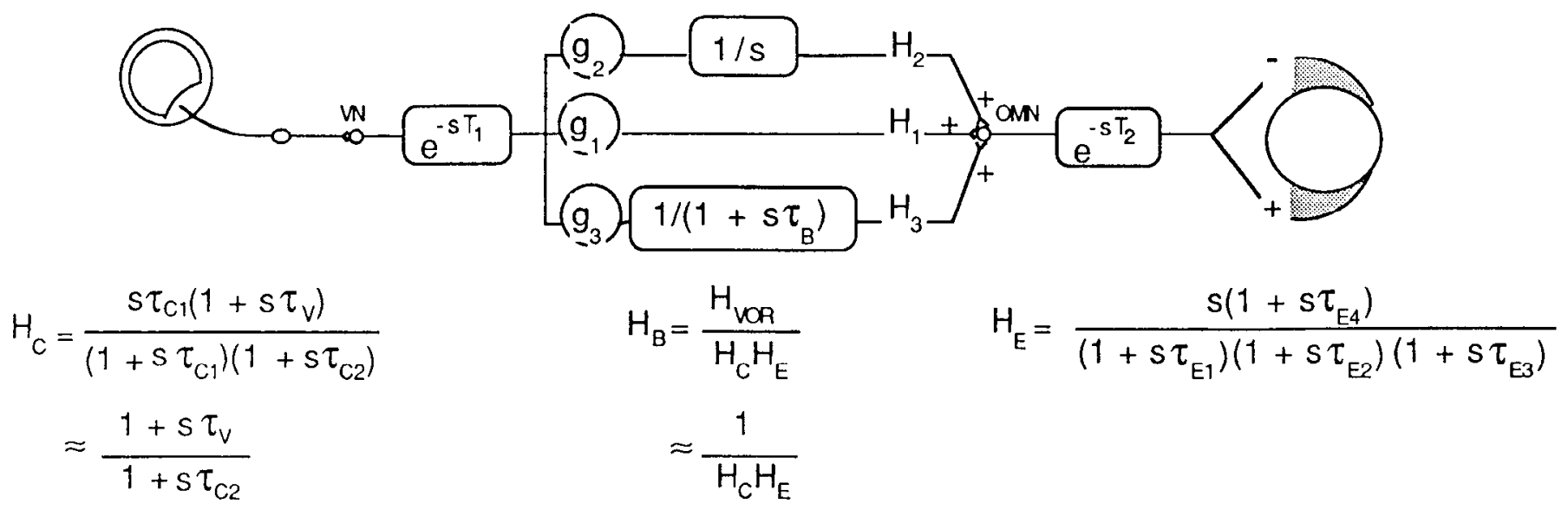

Figure 9. A block diagram of the VOR $\left(H_{\mathrm{vOR}}\right)$. Semicircular-canal afferents $\left(H_{C}\right)$ provide inputs to the vestibular nuclei ( $\left.V N\right)$. Central (or brain) pathways $\left(H_{B}\right)$ link VN with the oculomotor motor nuclei $(O M N)$, and the latter drive the oculomotor plant $\left(H_{E}\right)$. $H_{B}$ is composed of three pathways, arranged in parallel: a head-velocity pathway $\left(H_{1}=g_{1}\right)$, an eye-position pathway $\left(H_{2}=g_{2} / s\right)$, and a filtered eye-velocity pathway $\left[H_{3}=g_{3} /(1+\right.$ $\left.s \tau_{B}\right)$ ]. (In the present context, where we are mainly interested in the VOR, it would be equally correct to call $H_{2}$ a head-position pathway and $H_{3}$ a filtered head-velocity pathway.) $H_{C}$ is plotted with regard to head velocity; $H_{B}$ and $H_{E}$, with regard to eye velocity. There are two delays: one ( $T_{1}$ ) between head rotations and OMN, the other $\left(T_{2}\right)$ between OMN and eye movements; $T_{1}+T_{2}=14$ msec. The parameters for $H_{C}$ are $\tau_{C l}=6$ sec and $\tau_{C 2}=0.003 \mathrm{sec} ; \tau_{V}$ depends on the discharge regularity of the assumed afferent input (see Fig. 10). The parameters for $H_{E}$ are $\tau_{E 1}=0.28$ sec, $\tau_{E 2}=0.037 \mathrm{sec}, \tau_{E 3}=0.003 \mathrm{sec}$, and $\tau_{E 4}=0.14 \mathrm{sec}$ (Fuchs et al., 1988).

We are mainly interested in the operation of the reflex in the frequency range, $0.1-4 \mathrm{~Hz}$. Except at the lower end of this range $(<0.3 \mathrm{~Hz})$, the reflex is compensatory, that is, $H_{\mathrm{voR}} \approx 1$, whence

$$
H_{B} \approx 1 /\left(H_{C} \cdot H_{E}\right) \text {. }
$$

We consider the three transfer functions, $H_{C}, H_{E}$, and $H_{B}$, in turn.

Semicircular-canal afferents. In the frequency range of interest, the response dynamics of the afferents can be summarized by a transfer function with regard to angular head velocity, $H_{C}(s)$ $=H_{\mathrm{IP}}(s) \cdot H_{\mathrm{V}}(s)$ (Fig. 9; Fernández and Goldberg, 1971). The term $H_{\mathrm{TP}}(s)=\tau_{C 1} s /\left[\left(1+\tau_{C 1} s\right) \cdot\left(1+\tau_{C 2} s\right)\right]$, where $\tau_{C 2}=6 \mathrm{sec}$ and $\tau_{C}=0.003 \mathrm{sec}$, is the torsion-pendulum model of cupular motion and is the same for all fibers. Above $0.1 \mathrm{~Hz}, \tau_{C 1} s>1$, and it will be convenient to use the approximation $H_{\mathrm{TP}} \approx 1 /(1$ $+\tau_{C 2} s$ ), because then the reflex can be taken as compensatory even at the lower end of the frequency range. The other term, $H_{\digamma}(s)=1+\tau_{v} s$, introduces phasc leads and gain enhancements at high frequencies.

The high-frequency effects are more conspicuous, the more irregular the discharge of an afferent or, equivalently, the higher its $\mathrm{CV}^{*}$. Figure $10 \mathrm{~A}$ plots the phases for canal afferents responding to $2-\mathrm{Hz}$ sinusoidal head rotations. Included are data for the squirrel monkey (Lysakowski et al., 1988) and the rhesus monkey (S. G. Lisberger, personal communication). In both species, phase leads range from near- 0 values in the most regular units to $>45^{\circ}$ in the most irregular units. The results can also be expressed in terms of $\tau_{v}$, which varies from $<0.01$ to $>0.075$ sec as $\mathrm{CV}^{*}$ varies across the unit population from 0.020 to 0.60 (Fig. 10B). From the results of the present study, we can suppose that the afferents contributing to the VOR have $\mathrm{CV}^{*} \mathrm{~s}$ of 0.02 0.10 , with phase leads of $\approx 15^{\circ}$ (range, $5-25^{\circ}$ ) and $\tau_{V}$ values of $\approx 0.025 \mathrm{sec}$ (range, $0.005-0.045 \mathrm{sec}$ ).
Oculomotor plant. As originally described by Robinson (1962), the mechanics of the plant can be summarized by a fourth-order transfer function, which can be reduced to third-order by ignoring the relatively small inertia of the globe. Parameters of the transfer function have been deduced by a direct mechanical analysis in humans (Robinson, 1962) or by correlating the discharge of ocular motoneurons with eye movements in the rhesus monkey (Fuchs et al., 1988). The latter data are summarized in the caption to Figure 9.

Central pathways. The three transfer functions, $H_{C}, H_{B}$, and $H_{E}$, are plotted in Figure 11. The gains and phase lags of $H_{B}$, which were obtained from Equation 2, decrease with frequency. Skavenski and Robinson (1972) made a specific proposal as to how this might be accomplished (Fig. 9, with $g_{3}=0$ ). They suggested that some of the afferent signal is routed through a head-velocity pathway $\left[H_{1}(s)=g_{1}\right]$, and the rest through an eyeposition pathway $\left[H_{2}(s)=g_{2} / s\right]$ that mathematically integrates the signal (see Fig. 9, caption, for pathway terminology). Setting $g_{1}=\tau_{B}$ and $g_{2}=1$ gives $H_{B}(s)=\left(1+\tau_{B} s\right) / s$. It was further assumed that $H_{C}=1$ and that the oculomotor plant was a firstorder system, $H_{E}(\mathrm{~s})=s /\left(1+s \tau_{E I}\right)$. In this situation, $H_{\mathrm{VOR}}=[(1$ $\left.\left.+s \tau_{B}\right) / s\right] \cdot\left[s /\left(1+s \tau_{E 1}\right)\right]$, and perfect compensation results when $\tau_{B}=\tau_{E !}$. The Skavenski-Robinson formulation, besides simplifying the dynamics of the oculomotor plant, ignores (1) the high-frequency phase leads of afferents, (2) the second pole of the canal transfer function, and $(3)$ a reflex delay, $T_{\text {voR }} \approx 14$ msec. When these three factors are included, $H_{\mathrm{vOR}}=\left[\left(1+s \tau_{\nu}\right) /\right.$ $\left.\left(1+s \tau_{C_{2}}\right)\right] \cdot \exp \left(-s T_{\mathrm{vOR}}\right)$. The afferent lead term, $H_{V}=(1+$ $\left.s \tau_{V}\right)$, can compensate for the phase lags introduced by $T_{\mathrm{vOR}}$ and by the second pole when $\tau_{V} \approx T_{\mathrm{voR}}+\tau_{C 2}=0.017 \mathrm{sec}$, a value appropriate to regular afferents (Fig. 10B). Compensation is quite good over the bandwidth, $0.1-4 \mathrm{~Hz}$. As can be seen in Figure 12, $A$ and $D$, VOR gain is near unity, and VOR phase 

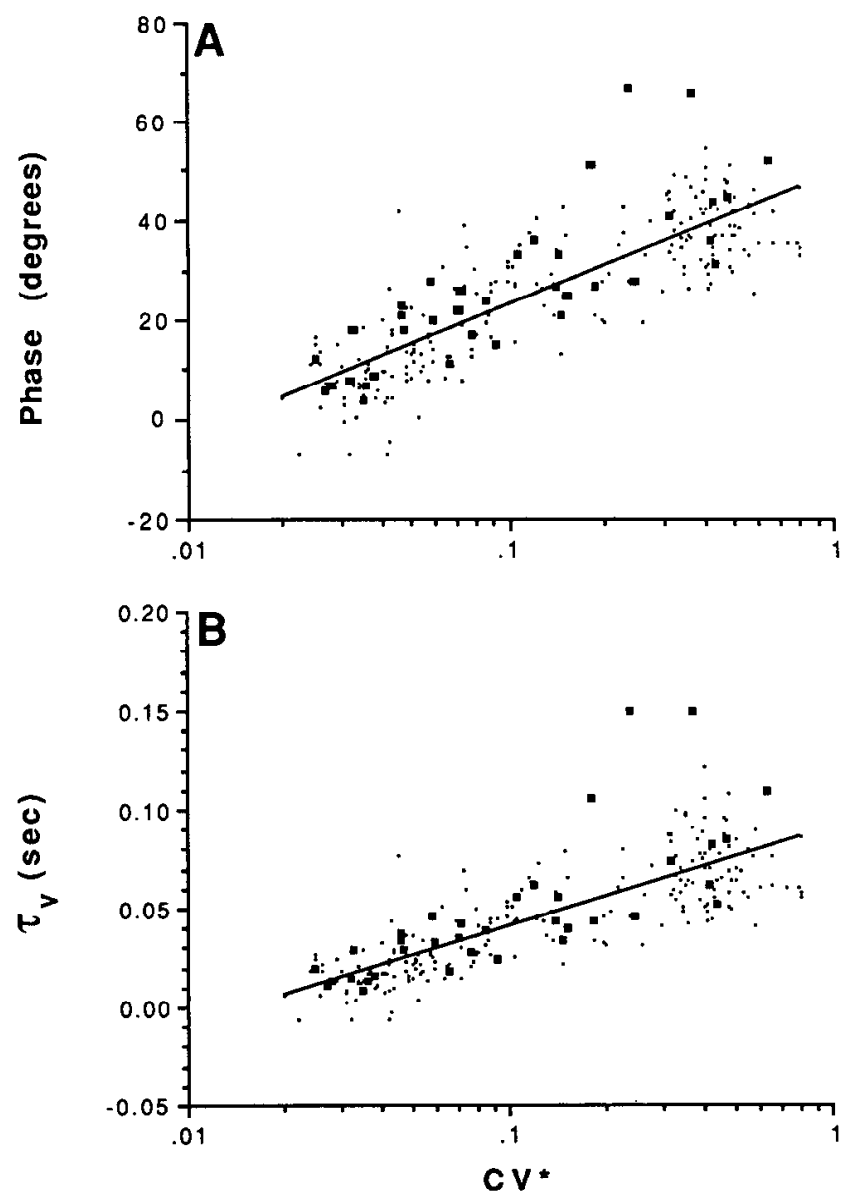

Figure 10. A, Relation between $\mathrm{CV}^{*}$ and response phase for vestibularnerve afferents in the squirrel monkey (small squares; Lysakowski et al., 1988) and in the rhesus monkey (large squres; data courtesy of $S$. G. Lisherger). Phases with regard to head velocity are for responses to $2-\mathrm{Hz}$ sinusoidal head rotations with phase leads positive. $B$, The phase data $(\phi)$ in $A$ are replotted in terms of $\tau_{\nu}$, the one free parameter in the semicircular-canal transfer function $\left(H_{C}\right.$ in Fig. 9). The rclation uscd was $\phi=90^{\circ}+\arctan \left(2 \pi f \tau_{Y}\right)-\arctan \left(2 \pi f \tau_{1}\right)-\arctan \left(2 \pi f \tau_{2}\right)$, where $f=2 \mathrm{~Hz}, \tau_{1}=6 \mathrm{sec}$, and $\tau_{2}=0.003 \mathrm{sec}$. Semilogarithmic regression lines were fit to the squirrel monkey data in $A$ and $B$.

is near 0 . Decreasing $\tau_{V}$ to 0 , as in the original SkavenskiRobinson treatment, results in a substantial phase lag in the reflex. Increasing $\tau_{V}$ to 0.080 , such as would occur were the afferent input from irregular afferents, causes an even larger phase lead.

The modified Skavenski-Robinson theory provides a rationale as to why regular units are especially suited to supply the afferent input to the VOR. Unfortunately, the theory is based on an inaccurate model of the oculomotor plant (Fuchs et al., 1988 ). When a more adequate model ( $H_{E}$ of Fig. 9$)$ is used, the simplified central circuit assumed by Skavenski and Robinson (1972) no longer provides a functionally adequate VOR. This is so regardless of the choice of the afferent input or of the assumed gains of the $H_{1}$ and $H_{2}$ pathways (Fig. $12 B, E$ ). To obtain good compensation, we found it necessary to include three parallel pathways in the reflex circuitry (Fig. 9). In addition to the head-velocity $\left(H_{1}\right)$ and eye-position $\left(H_{2}\right)$ pathways, there has to be a third or filtered eye-velocity pathway with a transfer function, $H_{3}(s)=1 /\left(1+\tau_{B} s\right)$. The third pathway produces an exponentially decaying or glide signal after an abrupt change in


Figure 11. Transfer functions, including gains $(A)$ and phases $(B)$, of the oculomotor plant $\left(H_{E}\right)$, the semicircular canals $\left(H_{C}\right)$, and the central (brain) pathways $\left(H_{B}\right)$ of the VOR $\left(H_{\mathrm{VOR}}\right) . \tau_{\nu}$, the one free parameter of $H_{C}$, was varied between 0.005 and $0.045 \mathrm{sec}$, the outer limits of its value for regular units (see Fig. 10); the corresponding variations in $H_{C}$ and $H_{B}$ are shown here. $H_{B}$ was calculated from Equation 2.

head or eye position. Such a signal is needed not only to produce a compensatory VOR, but also to generate accurate saccades (Goldstein, 1983; Optican and Miles, 1985). The existence of a third pathway is indicated by the presence of glide signals both in motoneurons (Goldstein, 1983; Fuchs et al., 1988) and in vestibular-nuclear neurons (Fuchs et al., 1988).

A three-pathway model can produce a compensatory VOR. Best compensation is obtaincd with $\tau_{V}=0.030 \mathrm{sec}$. For this value, VOR phase is near 0 throughout the frequency range (Fig. $12 F$ ), and gain is nearly constant (Fig. 12C). Almost equally good fits were obtained for $\tau_{V}=0.015-0.040 \mathrm{sec}$, still within the regular range. For other choices of $\tau_{v}$, there were larger errors, particularly in the gains at high frequencies (Fig. 12C). Because of the presence of more parameters, which can be adjusted to provide a compensatory VOR, the third-order model is more forgiving than is a first-order model and leads to smaller fitting errors. Even so, it can be concluded that the dynamic requirements of the reflex are best achieved when its afferent input comes from regular units.

The model can be used to calculate the relative contributions of the three pathways to the reflex. The contributions vary with stimulus conditions, which allows us to make inferences about the afferent input to the individual pathways. The $\mathrm{H}_{2}$ and $\mathrm{H}_{3}$ pathways are especially important during low-frequency sinusoidal rotations; the $H_{1}$ pathway, during high-frequency rotations. As an indication of this trend, the signals can be compared at 0.5 and $4 \mathrm{~Hz}$. At the lower frequency, the summed $\mathrm{H}_{2}+\mathrm{H}_{3}$ signal is seven to eight times larger than the $H_{1}$ signal; at the higher frequency, the former signal is only $1-1.5$ times larger. For rapid changes in head velocity, the contributions vary with time. This can be seen in Figure 13A, which dissects the model's eye-velocity response into $H_{1}$ and $H_{2}+H_{3}$ components. The $H_{1}$ signal dominates the first $20 \mathrm{msec}$ or so of the response. As the rotation continues, the $\mathrm{H}_{2}+\mathrm{H}_{3}$ signal becomes progressively more important. If different sets of afferents supplied the headvelocity $\left(H_{1}\right)$ and the other two $\left(\mathrm{H}_{2}\right.$ and $\left.\mathrm{H}_{3}\right)$ pathways, the ablating currents should have had different effects on the reflex responses to 0.5 - and 4-Hz sinusoids and on those occurring early and late during rapid changes in head velocity. Because the 

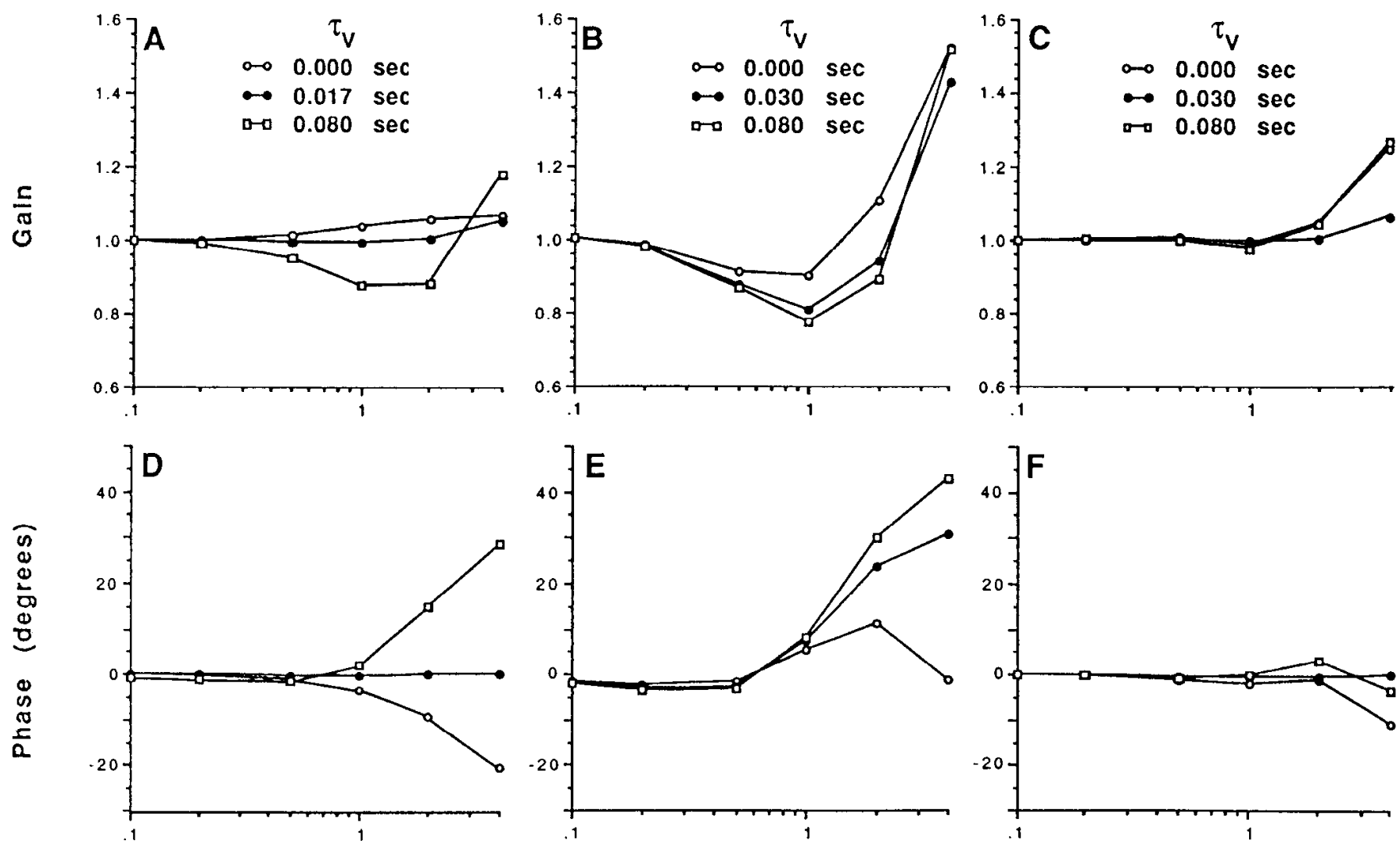

\section{Frequency $(\mathrm{Hz})$}

Figure 12. Transfer functions for various models of the VOR $\left(H_{\mathrm{voR}}\right)$, including gains $(A-C)$ and phases $(D-F)$. For each model, curves are shown for three assumed values of $\tau_{V}$, the one free parameter of the semicircular-canal transfer function $\left(H_{C}\right.$ in Fig. 9). Once $\tau_{V}$ was chosen, the parameters of the central pathways $\left(g_{1}-g_{3}\right.$ and $\tau_{B}$ in Fig. 9$)$ were adjusted to make $H_{\mathrm{VOR}}$ as compensatory as possible. $A$ and $D$, Modified Skavenski and Robinson (1972) model with a first-order oculomotor plant $\left[H_{E}=s /\left(1+s \tau_{E}\right)\right.$, where $\left.\tau_{E}=0.16 \mathrm{sec}\right]$ and with no filtered eye-velocity pathway $\left(g_{3}=0\right.$ in Fig. 9). Best compensation is achieved when the afferent input comes from regular units $\left(\tau_{V}=0.017 \mathrm{sec}\right) . B$ and $E$, Poor compensation is achieved when a third-order oculomotor plant ( $H_{E}$ in Fig. 9) is substituted for the first-order plant in $A$. This is so as long as the $H_{3}$ pathway is absent. $C$ and $F$, The $H_{3}$ pathway has been added. Best compensation is achieved with regular inputs $\left(\tau_{V}=0.030 \mathrm{sec}\right)$.

currents were uniformly ineffective, it would appear that regular afferents provide the major inputs to all three pathways.

Adaptive changes. Studies of adaptive plasticity may have a bearing on the afferent input to the VOR. Lisberger and Pavelko (1986) used optical lenses to modify the gain of the VOR, which was measured with rapid changes in head velocity. Responses became considerably more phasic as the gain was lowered from normal values and slightly less phasic when the gain was increased from these values (Fig. 13D). To explain their findings, Lisberger and Pavelko proposed that VOR pathways could be divided into modifiable and unmodifiable components. The change in response dynamics with gain was then explained by supposing that less phasic, regular afferents fed the modifiable pathway, whereas more phasic, irregular afferents supplied the unmodifiable pathway. The gain of the latter pathway was set to 0.3 . The modifiable response appeared $\approx 5 \mathrm{msec}$ after the start of the unmodifiable response, which led to the suggestion that the former involved a slower and possibly synaptically more complicated pathway.

The idea that irregular afferents are the major input to unmodifiable pathways would be difficult to reconcile with our results. One way out of the difficulty is to suppose that the more phasic input to unmodifiable pathways and the less phasic input to modifiable pathways both come from regular afferents. There are differences in the response dynamics of regular afferents (Fig. 10). Are these large enough to account for the observed changes in reflex dynamics? In the Lisberger-Pavelko (1986) theory, there is a strict relation between reflex and afferent dynamics. The observed changes in reflex dynamics with gain require that the afferents feeding the modifiable and unmodifiable pathways differ in their phases at $2 \mathrm{~Hz}$ by $30-35^{\circ}$ or, equivalently, in their $\tau_{V}$ values by $0.05-0.06 \mathrm{sec}$. To get such differences requires that the modifiable and unmodifiable inputs come from the extremes of the regular population depicted in Figure 10. The modifiable input must come from the least phasic $10 \%$ of the population $\left(\tau_{V} \approx 0\right)$, and the unmodifiable input, from the most phasic $10 \%$ $\left(\tau_{v} \approx 0.054 \mathrm{sec} ;\right.$ see Fig. 13D). The explanation would seem implausible because it excludes the most typical $80 \%$ of regular afferents from participation in the reflex.

Another interpretation is possible. Here, two assumptions are made: (1) the $H_{2}$ and $H_{3}$ pathways are modifiable, while the $H_{1}$ pathway is not; and (2) the same set of regular afferents supplies all three pathways. The first assumption is based on the observation that there is almost no change with gain state in the headvelocity signals carried by rotation-sensitive neurons in the vestibular nuclei (Lisberger and Miles, 1980), while there are marked changes in the corresponding eye-position and eye-velocity signals (Lisberger and Miles, 1980; Lisberger and Pavelko, 1988). 

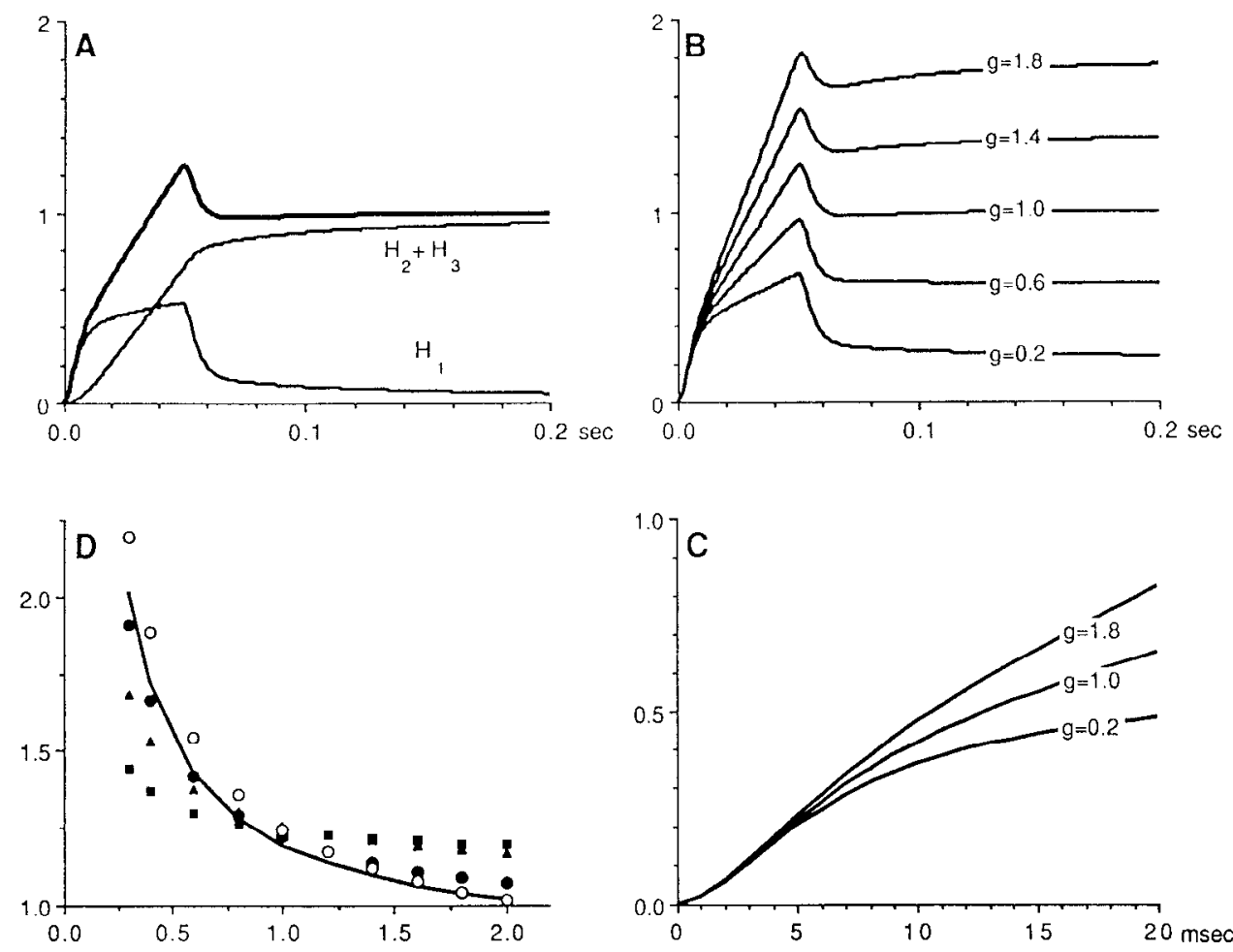

Figure 13. Calculated responses to a rapid $(50 \mathrm{msec})$ change in head velocity for a model of the VOR (Fig. $\left.12 C, F ; \tau_{v}=0.030 \mathrm{sec}\right)$. For $A-C$, the ordinate is normalized eye velocity; the abscissa, time from the start of the eye movement. $A$, The $H_{1}$ and $H_{2}+H_{3}$ components of Figure 9 are plotted separately for the normal response (steady-state VOR gain, $g=1$ ) plotted above as a thicker line. $B$, The gain of the $H_{1}$ pathway is kept constant, while the gains of the $H_{2}$ and $H_{3}$ pathways are changed by a factor of $g$, corresponding to the steady-state gain. $C$, The first 20 msec of three responses in $B$ are plotted on an expanded time scale. $D$, A dynamic index (ordinate), the ratio of the peak eye velocity to the plateau eye velocity, is plotted versus the plateau reflex gain (abscissa) for two models of the reflex. The curve is an empirical relation obtained by Lisberger and Pavelko (1986) to summarize their data. Points show calculations for two models. In the first model, the $H_{1}$ pathway is unmodified, while the $\mathrm{H}_{2}+\mathrm{H}_{3}$ pathways are modified (O; see Fig. $13 \mathrm{~B}$ ). The second model is modified from Lisberger and Pavelko (1986) so that the afferent inputs to the modifiable and unmodifiable pathways both come from regular units. For this purpose, regular afferents from the squirrel monkey were sorted in terms of their values of $\tau_{V}$ (Fig. 10B). Calculations are shown when the unmodifiable and modifiable inputs come, respectively, from the most and least phasic $10 \%(\bullet), 30 \%(\Delta)$, and $50 \%(\square)$ of the regular population. Under the last two conditions, the change in dynamic index with VOR gain is smaller than is actually observed.

The second assumption is consistent with the results of the present paper. As can be seen in Figure 13, $B$ and $D$, the model produces eye movements whose gain-related changes in response dynamics are similar to those observed by Lisberger and Pavelko (1986). The changes reflect the different frequency characteristics of the modifiable and unmodifiable pathways. When the VOR gain is increased, this enhances the low-frequency contributions of the modifiable pathways, so the reflex response becomes less phasic. Diminishing the VOR gain decreases this contribution, and there is a more phasic response. The modified response is delayed by $\approx 5 \mathrm{msec}$ from the start of the unmodified response (Fig. 13C). This is so even though it is assumed that the reflex delays are identical for all three pathways. The apparent delay in the modifiable response merely reflects the lowpass filter characteristics of the modifiable pathways.

Anatomical organization of the reflex. To produce a compensatory VOR requires that a precise combination of head-velocity, eye-position, and filtered eye-velocity signals be sent to motoneurons. The diagram of Figure 9 implies that each of the signals is sent over a separate pathway. This is a simplification because it is known that somc of the cyc-position signal $\left(R_{E}\right.$ in spikes $\left.\cdot \mathrm{sec}^{-1 / \mathrm{deg}}\right)$ and much of the head-velocity signal $\left(R_{H}\right.$ in spikes $\left.\cdot \mathrm{sec}^{-1} / \mathrm{deg} \cdot \mathrm{sec}^{-1}\right)$ are first combined in PVP cells before being sent to motoneurons (King et al., 1976; Tomlinson and Robinson, 1984). The $R_{E}$ signal carried by PVP cells is inade- quate for the normal operation of the reflex (Pola and Robinson, 1978). The required ratio, $R_{E} / R_{H}$ (in $\mathrm{sec}^{-1}$ ), on motoneurons is easily calculated. It has a value of $\approx 6 \mathrm{sec}^{-1}$ in the modified Skavenski-Robinson model and of $\approx 20 \mathrm{sec}^{-1}$ in the more accurate third-order model. In contrast, PVP cells have a ratio of $\approx 2.5 \mathrm{sec}^{-1}$ (Chubb et al., 1984; Tomlinson and Robinson, 1984). Presumably, the additional $R_{E}$ signal is provided by eye-movement related, oculomotor-projecting neurons located in any of several brainstem sites. The question arises as to why PVP cells carry only a small part of the $R_{E}$ signal. A satisfactory answer cannot be given. The reason is that PVP cells, besides projecting to the ocular motor nuclei, make collateral connections to many other brainstem nuclei (see, e.g., McCrea et al., 1987). The latter structures form part of a potentially vast network involved, among other things, in producing reflexive eye movements. The combination of signals carried by PVP neurons is apparently suited to the requirements of the entire network and cannot be understood simply in terms of the signals that have to be delivered to motoneurons.

\section{Concluding remark}

The present paper, by specifying the afferent input to the VOR, has allowed us to calculate the central transformation required to match this input to the motor output. The transformation can be summarized in terms of a simple systems model. It 
remains a challenge to understand the transformation in terms of the neuronal populations contributing to the reflex. One step in such an analysis might be provided by comparing the effects of the ablating currents on the discharge of secondary VOR neurons in alert animals. The analysis would be aided were it possible to determine the behavioral conditions under which the irregular inputs to the reflex make their presence felt.

\section{References}

Baird RA, Desmadryl GL, Fernández C, Goldberg JM (1988) The vestibular nerve of the chinchilla. II. Relation between afferent response properties and peripheral innervation patterns in the semicircular canals. J Neurophysiol 60:182-203.

Bilotto G, Goldberg J, Peterson BW, Wilson VJ (1982) Dynamic properties of vestibular reflexes in the decerebrate cat. Exp Brain Res 47:343-352.

Boyle R, Goldberg JM, Highstein SM (1991) Vestibular-nerve inputs to vestibulospinal and vestibulo-ocular neurons of the squirrel monkey. In: The head-neck sensory-motor system (Berthoz A, Graf W, Vidal PP, ed), in press. New York: Wiley.

Chubb MC, Fuchs AF, Scudder CA (1984) Neuron activity in monkey vestibular nuclei during vertical vestibular stimulation and eye movements. J Neurophysiol 52:724-742.

Ezure K, Cohen MS, Wilson VJ (1983) Response of semicircular canal afferents to sinusoidal polarizing currents: implications for inputoutput properties of second-order neurons. J Neurophysiol 49:639648.

Fernández C, Goldberg JM (1971) Physiology of peripheral neurons innervating semicircular canals in the squirrel monkey. II. Response to sinusoidal stimulation and dynamics of peripheral vestibular system. J Neurophysiol 34:661-675.

Fuchs AF, Kimm J (1975) Unit activity in vestibular nucleus of the alert monkey during horizontal angular acceleration and eye movement. J Neurophysiol 38:1140-1161.

Fuchs AF, Scudder CA, Kancko CRS (1988) Discharge patterns and recruitment order of identified motoneurons and internuclear neurons in the monkey abducens nuclei. J Neurophysiol 60:1874-1895.

Gacek RR (1969) The course and central termination of first order neurons supplying vestibular endorgans in the cat. Acta Otolaryngol [Suppl] (Stockh) 254:1-66.

Goldberg JM, Fernández C (1971) Physiology of peripheral neurons innervating semicircular canals in the squirrel monkey. III. Variation among units in their discharge properties. J Neurophysiol 34:676684.

Goldberg JM, Smith CE, Fernández C (1984) Relation between discharge regularity and responses to externally applied galvanic currents in vestibular nerve afferents of the squirrel monkey. J Neurophysiol 51:1236-1256.

Goldberg JM, Highstein SM, Moschovakis AK, Fernández C (1987) Inputs from regularly and irregularly discharging vestibular nerve afferents to secondary neurons in the vestibular nuclei of the squirrel monkey. I. An electrophysiological analysis. J Neurophysiol 58:700718 .

Goldstein HP (1983) The neural encoding of saccades in the rhesus moneky. PhD thesis, Johns Hopkins University.

Highstein SM, McCrea RA (1988) The anatomy of the vestibular nuclei. In: Neuroanatomy of the oculomotor system (Büttner-Ennever JA, ed), pp 177-202. Amsterdam: Elsevier.

Highstein SM, Goldberg JM, Moschovakis AK, Fernández C (1987) Inputs from regularly and irregularly discharging vestibular nerve afferents to secondary neurons in the vestibular nuclei of the squirrel monkey. II. Correlation with output pathways of secondary neurons. J Neurophysiol 58:719-738.

Kawai N, Ito M, Nozue M (1969) Postsynaptic influences on the vestibular non-Deiters nuclei from primary vestibular nerve. Exp Brain Res 8:190-200.
Keller EL (1976) Behavior of horizontal semicircular canal afferents during vestibular and optokinetic nystagmus. Exp Brain Res 24:459471.

Kevetter GA, Peracchio AA (1986) Distribution of vestibular afferents that innervate the sacculus and posterior canal in the gerbil. J Comp Neurol 254:410-424.

King WM, Lisberger SG, Fuchs AF (1976) Responses of fibers in medial longitudinal fasciculus (MLF) of alert monkeys during horizontal and vertical conjugate eye movements evoked by vestibular or visual stimuli. J Neurophysiol 39:1135-1149.

Lisberger SG, Miles FA (1980) Role of primate medial vestibular nucleus in long-term adaptive plasticity of vestibuloocular reflex. $\mathrm{J}$ Neurophysiol 43:1725-1745.

Lisberger SG, Pavelko TA (1986) Vestibular signals carried by pathways subserving plasticity of the vestibulo-ocular reflex in monkeys. J Neurosci 6:346-354.

Lisberger SG, Pavelko TA (1988) Brain stem neurons in modified pathways for motor learning in the primate vestibulo-ocular reflex. Science 242:771-773.

Louie AW, Kimm J (1976) The response of 8th nerve fibers to horizontal sinusoidal oscillations in the alert monkey. Exp Brain Res 24: 447-457.

Lysakowski A, Minor LB, Fernández C, Goldberg JM (1988) Physiological identification of calyx, dimorphic and bouton afferents in the vestibular nerve of the squirrel monkey. Soc Neurosci Abstr 14:172.

McCrea RA, Yoshida K, Berthoz A, Baker R (1980) Eye movement related activity and morphology of second order vestibular neurons terminating in the cat abducens nucleus. Exp Brain Res 40:468-473.

McCrea RA, Strassman A, May E, Highstein SM (1987) Anatomical and physiological characteristics of vestibular neurons mediating the horizontal vestibulo-ocular reflex of the squirrel monkey. J Comp Neurol 264:547-570.

Minor LB, Goldberg JM (1990) Influence of static head position on the horizontal nystagmus evoked by caloric, rotational and optokinetic stimulation in the squirrel monkey. Exp Brain Res 82:1-13.

Optican LM, Miles FA (1985) Visually induced adaptive changes in primate saccadic oculomotor control signals. J Neurophysiol 54:940958.

Paige GD (1983) Vestibuloocular reflex and its interaction with visual following mechanisms in the squirrel monkey. I. Response characteristics in normal animals. J Neurophysiol 49:134-151.

Pola J, Robinson DA (1978) Oculomotor signals in medial longitudinal fasciculus of the monkey. J Neurophysiol 41:245-259.

Precht W, Shimazu H (1965) Functional connections of tonic and kinetic vestibular neurons with primary vestibular afferents. J Neurophysiol 28:1014-1028.

Robinson DA (1962) The mechanics of human saccadic eye movement. J Physiol (Lond) 174:245-264.

Robinson DA (1970) Oculomotor unit behavior in the monkey. $\mathbf{J}$ Neurophysiol 33:393-403.

Robinson DA (1981) The use of control systems analysis in the neurophysiology of cyc movements. Annu Rev Neurosci 4:463-503.

Shimazu H (1972) Organization of commissural connections: physiology. In: Progress in brain research, Vol 37, Basic aspects of central vestibular mechanisms (Brodal A, Pompeiano O, eds), pp 177-190. Amsterdam: Elsevier.

Shimazu H, Precht W (1966) Inhibition of central vestibular neurons from the contralateral labyrinth and its mediating pathway. J Neurophysiol 29:467-492.

Skavenski AA, Robinson DA (1972) Role of abducens neurons in vestibuloocular reflex. J Neurophysiol 36:724-738.

Stein BM, Carpenter MB (1967) Central projections of portions of the vestibular ganglia innervating specific parts of the labyrinth in the rhesus monkey. Am J Anat 120:281-318.

Tomlinson RD, Robinson DA (1984) Signals in vestibular nucleus mediating vertical cyc movements in the monkey. J Neurophysiol 51:1121-1136.

Wilson VJ, Wylie RM, Marco LA (1968) Synaptic inputs to cells in the medial vestibular nucleus. J Neurophysiol 31:176-185. 